\title{
ARQUEOLOGIA E MAGIA
}

\author{
Tiago Brentam Perencini ${ }^{1}$
}

Resumo: A natureza não deixa nada sem assinar. Parece haver, no gesto da emissão de sinais, um propósito ético que pouco pode ser compreendido à luz das ciências humanas. Pensando diferente do registro científico, o objetivo geral deste artigo será descrever o jogo de penumbra pela qual a arqueologia de Michel Foucault aproxima-se do paradigma da magia. A magia é uma prática espiritual consigo, com o outro e com o mundo, que não se pode reduzir à representação e à significação. A hipótese que levanto busca averiguar em que medida o paradigma da magia é presente nos escritos arqueológicos de Michel Foucault, ainda que o pensador francês pouco se refira diretamente a ele, tarefa que implica uma escavação sobre os rastros deixados nas entrelinhas de seu pensamento, como fez seu contemporâneo Giorgio Agamben. Para tanto, enfocarei a ressonância existente entre os conceitos de (a) enunciado e assinatura e (b) a priori histórico e mana. Sabemos que enunciado e a priori histórico são dois operadores centrais ao pensamento arqueológico. Minha tarefa será mostrar que eles são íntimos à assinatura e à mana, ambas noções provenientes do campo da magia. Não será difícil percebermos que a arqueologia bebe no paradigma da magia ao ponto de se embriagar, o que permite pensar com saberes e práticas que foram eclipsados desde o pensamento secularizado e o iluminismo. Dessa maneira, a Arqueologia se inscreve como um ethos ainda a ser desvendado, espécie de anticiência das assinaturas.

Palavras-Chave: arqueologia - magia - enunciado - assinatura - Michel Foucault.

Michel Foucault empreendeu um gesto ético-político ao cruzar saberes, discursos e práticas sujeitadas que vigoram na cronologia ocidental a fim de identificar nelas o seu potencial de resistência e de lutas transversais. Isso porque a arqueologia não me parece apenas um procedimento de pesquisa, mas implica também outra atitude filosófica em tornar visíveis subjetividades que se diferem à maneira cientifica e institucional que configura o nosso pensamento no tempo presente.

1 Doutorando pelo Programa de Pós-Graduação em Educação da Unesp, campus de Marília-SP, com financiamento de pesquisa pela CAPES e sob a orientação do Prof. Dr. Pedro Angelo Pagni (UNESP/Marília) e co-orientação de Alexandre Simão de Freitas (UFPE). E-mail: tiagaobp@yahoo.com.br. 
Como comentadores, temos feito todo um esforço para mostrar que a arqueologia foucaultiana diferencia-se de outras disciplinas e campos de saberes tais como a psicologia, a linguística, o marxismo e as próprias ciências humanas ${ }^{2}$. Não obstante, teço nesse artigo uma postura contrária a essa, uma vez que não procuro diferenciar a arqueologia dos campos anteriormente instaurados, mas sim de mostrar como ela se aproxima de um paradigma eclipsado historicamente pela maneira ocidental, científica e humana de pensar: a magia. Nesses termos, ela não constituiria apenas um procedimento de pesquisa, com vistas a resgatar saberes e práticas marginais, mas incide principalmente enquanto campo epistemológico que possibilita um questionamento ético sobre a maneira como temos vivido no tempo presente.

A magia pode ser descrita como uma arte das mudanças dos estados dos seres e das coisas com a finalidade de alterar a realidade posta na tentativa de se comunicar e criar mundos paralelos. Dessa maneira, ela contribui para repensarmos a dimensão humanista em que estamos confinados no presente, pois ela se cria nos exercícios que resultam de um trabalho de experimentações ativas, sempre abertas ao imponderável e ao imprevisível de forças e potências atuantes aqui e agora. Ela não se atém à busca da verdade como autoconhecimento, além de poder ser praticada desde uma miríade de possibilidades, como as preces e evocações, as danças, o sexo, as fermentações, preparos alquímicos etc. desde que ativem um símbolo com a intenção de promover transformação naquilo que está vivo ${ }^{3}$.

Ao se aproximar da magia, a arqueologia pode ser pensada como uma "anticiência das assinaturas", se entendermos por "assinatura" uma espécie de função de existência que articula certa terapêutica dos sinais que são enviados ao sujeito para transformar-se em outro diferente daquilo que é, sinais que embora tenham uma racionalidade própria, não podem ser configurados em termos de uma categorização científica à maneira binária tal como ainda vigora na atualidade. Persigo com isso a pista deixada por Alexandre Filordi de Carvalho, ao apontar que "tanto arqueologia quanto genealogia são a dupla face de uma luta contra o método, ou, ainda, a demarcação de uma postura anticiência, ou, também, a produção de ferramentas de trabalho no sentido de um antimétodo (...)"s.

\footnotetext{
2 Tenho investigado a arqueologia foucaultiana enquanto procedimento de pesquisa faz uma década. Seguem as referências a estudos produzidos por mim acerca dessa temática em específico: PERENCINI, O enunciado no pensamento arqueológico de Michel Foucault, PERENCINI, Uma arqueologia do ensino de filosofia no Brasil: Formação discursiva na produção acadêmica de 1930 a 1968. Sugiro também Cf. DREYFUS, H. RABINOW, P. Michel Foucault: Uma Trajetória Filosófica; LECOURT, A Arqueologia e o Saber; MACHADO, A arqueologia do saber e a constituição das ciências humanas; Foucault, a ciência e o saber.

${ }^{3}$ Essa visão de magia aproxima-se das obras de FEDERICI, Calibã e a bruxa; STENGERS, No tempo das catástrofes; Reativar o animismo.

${ }^{4}$ Essa expressão foi pensada a partir de um trecho extraído de AGAMBEN, Signatura rerum, p. 90, quando o autor afirma que a arqueologia é uma ciência das assinaturas. Mantenho a concordância com o pensador italiano sobre as assinaturas, mas persigo a pista de que a arqueologia vem funcionar em um caráter anticientífico, não no sentido daquilo que se opõe binariamente à ciência, mas apostando em uma diferença substancial da compreensão científica que vigora na atualidade.

${ }^{5}$ CARVALHO, Anarqueologia e aleturgia em Foucault, p. 71. Vale a nota de que o autor refere-se aqui à tentativa de pensar certa anarqueologia em Michel Foucault, algo que tenho perseguido em minha tese de doutoramento, que conta por título provisório: Educação, Filosofia e Magia: Uma anarqueologia do cuidado de si entre o daimon e os sonhos. Não enfocarei a anarqueologia nesse artigo, pois foge aos propósitos temáticos desse dossiê.
} 
Ao assumir a aposta foucaultiana de promover estratégias para criar maneiras de pensamento diferentes do método científico dissolvemos os eixos demarcatórios entre "primeiro, segundo ou terceiro Foucault. Ou como é comum afirmar a comentografia foucaultiana, eixos de preocupações acerca do saber, do poder ou da ética, espécie de trindade já consagrada" (itálico do autor) ${ }^{6}$, o que implica considerarmos que a busca por relações com a verdade e com outras formas de vida estariam presente desde os textos iniciais de sua produção, bem como seria possível uma analítica dos saberes incorrendo por seus cursos de maturidade no Collège de France.

Ademais, tal aposta toma ainda o projeto filosófico de Michel Foucault como manifestações de seu exercício espiritual em andamento ${ }^{7}$. Ainda que o pensador francês tenha privilegiado a terminologia da espiritualidade em detrimento da magia, é preciso notar que existe um elo indissociável entre uma e outra, sendo a magia uma espécie de campo desaguador de técnicas que permitem a transformação da psique (alma), abrindo assim novos acessos à maneira de pensar e praticar a espiritualidade como forma de orientação no mundo pelos sinais emanados pelo cosmo à psique. Se o real da filosofia é a espiritualidade, entendida como exercício de si sobre si $^{8}$, será preciso problematizar e criar técnicas de si que tornem íntimos os paradigmas da filosofia e da magia, algo que tenho tomado por horizonte não apenas de pesquisa, mas também de vida, uma vez que pratico cotidianamente a leitura filosófica da magia desde o cruzamento entre práticas silenciadas pelos saberes acadêmicos, como a tarologia e a astrologia? .

Posto isso, tomo por objetivo geral desse artigo a descrição sobre como a arqueologia aproxima-se intimamente ao paradigma da magia, primeiro porque noções e conceitos empregados por Michel Foucault são definitivamente "roubados" desse universo, depois, pois a própria maneira de pensar arqueologicamente se diferencia da racionalidade científica. A magia é uma forma de relação com o mundo que não se pode reduzir à representação e à significação.

A hipótese que levanto busca averiguar por quais formas o paradigma da magia está presente nos escritos arqueológicos de Michel Foucault, ainda que esse pensador pouco se refira diretamente a ele. Essa identificação implica o gesto de escavação sobre o próprio pensamento arqueológico, incorrendo não raras vezes pelos sinais deixados nas entrelinhas de seu pensamento, abrindo fendas generosas para que pudéssemos ver e dizer contemporaneamente, com outros autores que deram seguimento ao projeto filosófico de Foucault para além de seu a priori histórico, como é o caso de Giorgio Agamben ${ }^{10}$. Vale a observação de que sei o quanto uma arqueologia filosófica aos moldes desse autor se difere,

\footnotetext{
${ }^{6}$ CARVALHO, Anarqueologia e aleturgia em Foucault, p. 72

${ }^{7}$ FREITAS, "O cuidado de si e os perigos de uma ontologia ainda sem cabimento: o legado ético-espiritual de Foucault”, p. 130.

${ }^{8}$ CARVALHO, "Foucault e a espiritualidade como o real da filosofia".

9 Sei que um tipo de declaração íntima como essa foge ao decoro acadêmico, mas decidi mantê-la com o um propósito ético-político claro de mostrar que vida e pesquisa em filosofia não se separam. As reflexões ancoradas nesse artigo, por exemplo, só foram possíveis porque a prática diária da magia conduziu-me a ele. Trata-se de um processo de experimentação em pleno movimento. Divulgo, porém, um artigo que escrevi oriundo de minha participação em um Congresso de Psicologia Analítica Junguiana. Cf. PERENCINI, "O tarot como prática possível ao processo de individuação".

${ }^{10}$ Cf. AGAMBEN, Signatura rerum.
} 
ainda que não se distancie ou dissone, em seu entendimento, da arqueologia do saber foucaultiana. Nesse sentido, tomarei as considerações de Agamben naquilo que me permite pensar sobre o legado da arqueologia do saber, simplesmente.

A especificidade desse artigo será tornar visível outro jogo de pensamento que teve de ser silenciado para que uma verdade científica e humana fecundasse nossa maneira institucional de operar na atualidade. Para tanto, enfocarei a ressonância existente entre os conceitos de (a) enunciado e assinatura e (b) a priori histórico e mana. Sabemos que enunciado e a priori histórico são dois operadores caros ao pensamento arqueológico foucaultiano. Minha tarefa será mostrar que eles são íntimos à assinatura e mana, ambas noções provenientes do campo da magia. Em essência, não será difícil percebermos que o procedimento arqueológico bebe ao ponto de se embriagar do universo encantado da magia, campo que poderia nos levar a trilhar não apenas por outras relações com a epistemologia, mas também a dar vazão a diferentes formas de vida insurgentes na contemporaneidade.

\section{LEITURA DE PENUMBRA: ESCAVAR RESSONÂNCIAS ENTRE A ARQUEOLOGIA E O PARADIGMA DA MAGIA}

A arqueologia foucaultiana é um procedimento analítico que visa libertar-se do tema antropológico e com isso se tece enquanto uma história filosófica que busca pela acontecimentalização das epistemes e dos saberes que emergem e desaparecem enigmaticamente, cortados de suas raízes pela cronologia ocidental. Como ato filosófico, ela aposta não apenas em descrever aquilo que foi, mas em inventar os acontecimentos que deveriam ou poderiam ter sido. A noção de acontecimento convida à emergência da novidade como possibilidade de libertar a história da sua dimensão humanista, que confina o tempo à compreensão causal, continuísta, progressista, teleológica e dualista, prática ainda vigorante em nossa maneira científica e institucional de pensar. Diferente disso, a arqueologia aposta na identificação da singularidade dos saberes emergentes em determinada época e espaço, que permitiram aos sujeitos poderem viver de uma determinada maneira que não de outra.

Arqueo flerta aos arquivos, a existência acumulada dos discursos, rastros de pensamento que nos indicam direções não limitadas pelo tempo cronológico. De outro modo, os arquivos são, em certa medida, sempre arcaicos, conforme cruza passado, presente e futuro. Tais arquivos não são próprios de uma estrutura metahistórica intemporal, mas obedecem aos jogos, correntes e forças operantes na história. Tomando nota de que o pensamento produz discursos e de como estes se passam por verdadeiros ao longo do tempo, o arqueólogo reúne os arquivos não para buscar neles uma interpretação, mas sim para compreender as condições de possibilidades para os sujeitos afirmarem determinado discurso que excluiu outras manifestações do verdadeiro. Cartografar os discursos - aquilo que as pessoas realmente fazem e pensam, mas sem o saber - visa descobrir a singularidade desse acontecimento.

A tarefa arqueológica descarta de antemão a existência de qualquer universal e procura identificar as rupturas e descontinuidades inerentes ao solo sobre o qual uma verdade foi demarcada. Para essa prática de pesquisa não existe passado sancionado ou ultrapassado. Por isso se faz necessária uma leitura de penumbra entre os limiares de epistemologização e os campos de saberes, contrariando a atualidade científica que assume certa evolução e 
progresso do discurso, comparado às formas de nos relacionarmos com as práticas e saberes do passado.

A leitura arqueológica imprimida por Foucault permite escapar à interpretação tradicional da história das ideias, que reduz a magia às formas de conhecimento supersticiosas e identifica o século XVII como aquele em que tais crenças desaparecem a fim de possibilitar a entrada da natureza científica na relação com o saber e o mundo. Foucault, ao contrário, oferece-nos uma perspectiva bem diferente dessa porque não considera a magia como um mero efeito residual da consciência europeia feudal, mas aposta nesse pensamento como uma forma de conhecimento que não pode ser confinado à representação e à significação.

Ora, a magia é uma forma de pensamento eclipsada desde o século XVII justamente porque não se configura nos termos universais da razão e da verdade. Seguindo a pista foucaultiana, Esther Díaz torna clara a motivação principal pela qual a possibilidade de acesso ao conhecimento da magia encontrou o seu declínio:

A magia pertence ao erro. O censurável do erro é que ele produz engano. Trata-se, também, de um escárnio à razão. A magia perdeu o atributo de ser eficaz. Converteu-se em palavreado vazio de conteúdo, em rito vão. Passou ao campo da ilusão, porque não tem realidade e porque cega aquele que carece de espírito reto e vontade firme. A condenação ética conseguiu neutralizar a eficácia da magia. Ao tornar a crença culpável, a magia perdeu credibilidade. Essa articulação entre erro e falta moral mais adiante se converterá em neurose. ${ }^{11}$

Além de não se adequar aos pressupostos modernos do momentum cartesiano, a magia também se excede à concepção de ciências humanas que englobou a psicanálise e o marxismo.

A leitura arqueológica impressa em Aspalavras e as coisas evidencia como a arquitetura científica na qual se ancorou todo um discurso de evolução do pensamento ocidental desde os séculos XVII implicou no apagamento da magia como maneira de conhecer o mundo habitado. Nessa obra, Foucault entende que será preciso nos determos melhor em tal paradigma, modelo presente desde antes dos gregos até o século XVI, pois ele opera em uma forma de se relacionar com o conhecimento que ultrapassa os limites da linguagem confinada entre sujeitos e objetos.

A magia é uma forma de aprendizado íntima ao paradigma da semelhança ${ }^{12}$, uma relação estabelecida com o conhecimento que inclui os saberes sujeitados das pessoas em

\footnotetext{
${ }^{11}$ DÍAZ, A filosofia de Michel Foucault, p. 63.

${ }^{12}$ Tal paradigma remonta à Grécia Arcaica como uma forma de pensamento mágico que se relaciona à emergência da filosofia no Ocidente (GERNET, Antropología de la Grecia Antigua, p. 367). Da mesma maneira com que a natureza engendra semelhanças, é conferido ao homem o dom de ascender à divindade, ou melhor, o caminho da existência seria um meio de divinação onde o homem traz em si a potência de semelhança entre o mortal e o divino. Walter Benjamin dedicou-se a escrever sobre a doutrina das semelhanças em diferentes textos em que aborda a magia (Destino e caráter; Magia e técnica, arte e política). Nesse contexto, o homem seria um microcosmo instalado no macrocosmo e a vida não seria mera obra do acaso, mas uma possibilidade de aprendizado conferida a sua alma. O momento do nascimento seria o ajustamento sincrônico à ordem cósmica que permite aos saberes divinatórios
} 
suas formas locais de pensar e sentir como práticas com racionalidades próprias que criam um tipo singular de saber. Para essa forma de conhecer, o mundo seria "coberto de signos que é preciso decifrar, e estes signos, que revelam semelhanças e afinidades, não passam, eles próprios, de formas de similitudes" "13 que se cruzam infinitamente, criando possibilidades novas de conhecimento. Não se trata de uma forma científica com a verdade, que confina a nossa maneira de conhecer ao dualismo e binarismo (ou/ou), mas aposta nas analogias (e/e) e na multiplicidade dos seres.

A leitura arqueológica mostra que esse corpus de semelhança era meticulosamente organizado até o século XVI, ainda que para os nossos olhos contemporâneos toda essa rede de saber pareça sofrivelmente confusa. A leitura filosófica que teço possibilita não apenas averiguar como a arqueologia estabelece uma íntima relação conceitual e procedimental com a magia, mas também expandi-la como terapêutica não restrita às interpretações ocultistas, que a confinaram à revelação e à salvação. Como consta em As palavras e as coisas, há ao menos cinco noções fundamentais a conduzir o paradigma da magia na era da semelhança: convenientia, emulatio, analogia, simpatia e assinatura ${ }^{14}$.

A convenientia é uma semelhança ligada ao espaço na forma de aproximação. Os signos do mundo estabelecem parentescos uns com os outros e possibilitam comunicações entre os seres. Nessa perspectiva, alma e corpo, humanos, animais e vegetais, não se classificam como duas coisas opostas e separadas, mas se avizinham para estabelecerem comunicação entre as suas diferenças; o corpo conversa com a alma e a alma conversa com o corpo. "Na vasta sintaxe do mundo, os diferentes seres se ajustam uns aos outros; a planta comunica com o animal, a terra com o mar, o homem com tudo o que o cerca" ${ }^{15}$ e por isso vemos crescer "plantas nos galhos dos cervos, espécie de ervas no rosto dos homens" 16 . O mundo seria uma conveniência comum onde os seres se comunicam sem a centralidade do humano.

A emulatio é a segunda forma de semelhança, liberada da lei do espaço, onde coisas dispersas através do mundo se correspondem. O modelo de homem de Paracelso, por exemplo, encontra nos astros a sua dobra. O rosto humano espelharia o céu:

Os dois olhos, com sua claridade ilimitada, refletem a grande iluminação que, no céu, expandem o Sol e a Lua; a boca é Vênus, pois que por ela passam os beijos e as palavras de amor; o nariz dá a minúscula imagem do cetro de Júpiter e do caduceu de Mercúrio. Por esta relação de emulação, as coisas podem se imitar de uma extremidade à outra do universo sem encadeamento nem proximidade ${ }^{17}$.

como a astrologia e a quiromancia decifrarem o daimon (gênio mimético aliado ao dom) da presente vida da alma. Nesse contexto, cada alma percorre um tipo de jornada singular para o aprendizado das virtudes.

${ }^{13}$ FOUCAULT, As palavras e as coisas, p. 44.

${ }^{14} \mathrm{O}$ universo da magia encontra-se muito para além das quatro leis de semelhanças à maneira como Foucault nos apresenta e elas mereceriam um estudo pormenorizado, que só não farei agora porque esse artigo obedece a outros propósitos. Cf MAUSS, Sociologia e antropologia.

${ }^{15}$ FOUCAULT, As palavras e as coisas, p. 24.

${ }^{16}$ FOUCAULT, As palavras e as coisas, p. 24.

${ }^{17}$ FOUCAULT, As palavras e as coisas, p. 27. 
O homem paracelsiano é constelado de astros, mas não está confinado e determinado por ele. Pelo contrário, o homem descobrirá que contém as "estrelas no interior de si mesmo (...), e que assim carrega o firmamento com todas as suas influências" 18 e as virtudes necessárias para a sua orientação no mundo. A emulação seria uma espécie de espelho refletido por meio do qual as coisas dispersas no mundo se correspondem. Da mesma maneira como o homem espelha em si os astros e pode buscar a sua ascese na comunhão com eles, as estrelas seriam uma espécie de planta celeste em formato espiritual que olham para a terra como um reflexo daquilo que procriaram e podem the conferir virtudes particulares ${ }^{19}$.

A analogia é a terceira forma de similitude, que supõem a convenientia e aemulatio como formas de comunicação entre seres não materiais e por isso transcende aquilo que é existente aos sentidos. A analogia opera em coisas que não são necessariamente visíveis, materiais e palpáveis e por isso se entremeia a esfera mais sutil das relações e das forças. Ela possibilita a união entre mundos diferentes. "O espaço das analogias é, no fundo, um espaço de irradiação" ${ }^{20}$ de propagação de forças que emitimos, somos por elas envolvidos e por elas todas as figuras entre mundos podem se aproximar.

O homem, nessa perspectiva, não passa de um animal bumano que emite propagações e as recebe da mesma maneira que emitem e recebem outros animais, as plantas, a terra, os metais e as tempestades. O homem

[e]stá em proporção com o céu, assim como os animais e as plantas, assim como a terra, os metais, as estalactites ou as tempestades. Erguido entre as faces do mundo, tem relação com o firmamento (seu rosto está para o seu corpo como a face do céu está para o éter; seu pulso bate-lhe nas veias como os astros circulam segundo suas vias próprias; as sete aberturas formam o seu rosto o que são os sete planetas do céu) ${ }^{21}$.

O homem não ocuparia a função superior em relação aos outros seres, mas é uma criação análoga à terra em que habita, "sua carne é uma gleba, seus ossos, rochedos, suas veias, grandes rios, sua bexiga é o mar e seus sete membros principais, os sete metais que se escondem no fundo das minas"22.

A analogia se difere consideravelmente do princípio dicotômico que domina a lógica ocidental. Contra a alternativa drástica "ou A ou B", que exclui o terceiro, a analogia ensinanos pelo "A $e \mathrm{~B}$ ", "nem $\mathrm{A}$, nem $\mathrm{B}$ " e dessa maneira permite que transformemos os binarismos (particular/universal; forma/conteúdo; masculino/feminino, etc.) em campos de forças. De modo parecido ao que ocorre em um campo eletromagnético, as tensões polares perdem a sua identidade substancial abrindo espaço para as zonas de indecidibilidade, aquilo que não pode ser identitário a priori. A partir da noção de analogia, a magia convida-nos a transportar a nossa maneira dicotômica de pensar - construída pelos quantitativos, qualitativos e pelas

\footnotetext{
18 PARACELSO apud FOUCAULT, As palavras e as coisas, p. 28.

${ }^{19}$ FOUCAULT, As palavras e as coisas, p. 27 e 28.

${ }^{20}$ FOUCAULT, As palavras e as coisas, p. 31.

${ }^{21}$ FOUCAULT, As palavras e as coisas, p. 30.

${ }^{22}$ FOUCAULT, As palavras e as coisas, p. 30.
} 
hierarquias de valores - para o campo das intensidades vetoriais nas relações entre os seres ${ }^{23}$. A literatura seria uma das formas principais de movimentação analógica entre as palavras para a criação de novos mundos e por isso se enreda intimamente na maneira mágica de pensar.

A simpatia é a quarta forma de semelhança. Ela é um princípio de mobilidade que permite ligar as coisas umas às outras por um movimento exterior e visível - atrai o que é pesado para o peso do solo e o que é leve para o éter sem peso - e suscita em segredo um movimento interior:

O fogo, porque quente e leve, se eleva ao ar, para o qual as chamas infatigavelmente se erguem; perde, porém, sua própria secura (que o aparentava a terra) e adquire assim certa umidade (que o liga à agua e ao ar); desaparece então em ligeiro vapor, em fumaça azul, em nuvem: tornou-se $\operatorname{ar.~}^{24}$

Dentro do universo simpático "nenhum caminho é de antemão determinado, nenhuma distância é suposta, nenhum encadeamento prescrito. A simpatia atua em estado livre nas profundezas do mundo" porque não se limita ao espaço e ao tempo atuado, mas "suscita o movimento das coisas no mundo e provoca a aproximação das mais distantes" por sua afinidade ${ }^{25}$, como a atração recíproca da flor de girassol que se vira em direção ao nascer do sol.

Foucault alerta-nos de que a simpatia tem o perigoso poder de assimilar às coisas em relação às outras coisas e, por isso, poderia transformar e alterar, mas continuar sendo uma direção do idêntico, do Mesmo, o que acarretaria no desaparecimento da singularidade das coisas. "Eis porque a simpatia é compensada por sua figura gêmea, a antipatia. Esta mantém as coisas em seu isolamento e impede a assimilação; encerra cada espécie na sua diferença obstinada e na sua propensão a preservar no que é" ${ }^{\prime 26}$. Desse modo, existe um contrabalancear constante entre simpatia e antipatia que garante que as coisas possam se aproximar uma das outras sem, contudo, dissipar-se, preservando a sua singularidade.

O elemento do fogo é quente e seco; tem, portanto, antipatia pelos da água, que é fria e úmida. O ar quente é úmido, a terra fria é seca, eis a antipatia. Para conciliá-los, o ar foi colocado entre o fogo e a água, a agua entre a terra e o ar. Enquanto é quente, o ar se avizinha do fogo e sua umidade se acomoda com a da água ${ }^{27}$.

O jogo polar entre simpatia e antipatia enreda-se pela dispersão, movimento apto à garantir que as semelhanças não reduzam entre si as diferenças e as singularidades de seres. Em suma, as semelhanças permitem ligar as coisas e os seres singulares entre si.

\footnotetext{
23 AGAMBEN, Signatura rerum, p. 24 e 25.

${ }^{24}$ FOUCAULT, As palavras e as coisas, p. 32.

${ }^{25}$ FOUCAULT, As palavras e as coisas, p. 32.

${ }^{26}$ FOUCAULT, As palavras e as coisas, p. 33.

${ }^{27}$ FOUCAULT, As palavras e as coisas, p. 34.
} 
O recuo ao paradigma da semelhança encontra ressonância aos propósitos deste artigo por dois motivos: (a) tornar visível outros jogos de pensamento que tiveram de ser silenciados para que uma verdade científica e humana tremulasse em nossa maneira institucional de operar na atualidade e (b) grifar que o procedimento arqueológico bebe ao ponto de se embriagar no universo da magia, exposição que ficará mais evidente com as noções de assinatura e a priori histórico como analisadas a seguir.

\section{ASSINATURA E ENUNCIADO}

A assinatura é a última forma de semelhança grafada por Foucault ${ }^{28}$, e talvez a mais importante, uma vez que ela estabelece relação direta com o enunciado, conceito central para a arqueologia. Agamben vem mostrar que Foucault extrai o conceito de enunciado das assinaturas ${ }^{29}$, que fazem eco à maneira como os gregos relacionavam-se aos sinais, uma vez que os sinais não se reduzem à esfera semântica ou representacional.

A mesa redonda nomeada Nieţssche, Fred e Marx, proposta em 1967, exemplifica melhor a questão:

Ela ultrapassa sua forma propriamente verbal, que há certamente no mundo outras coisas que falam e não são linguagem. Afinal, é possível que a natureza, o mar, o sussurro das árvores, os animais, os rostos, as máscaras, as facas cruzadas, tudo isso; talvez haja linguagem se articulando de uma maneira que não seria verbal. Isso seria, se vocês querem, muito grosseiramente, o semainon dos gregos. ${ }^{30}$

Foucault vem pensar essa hermenêutica dos sinais (semainon) nos termos do enunciado como uma espécie de assinatura que os signos recebem pelo direito de existirem e serem usados com certa finalidade ética, a fim de orientar a psique em sua caminhada existencial, atinente à relação que o sujeito estabelece consigo mesmo. Ele quer nos mostrar que os enunciados não estão longe de nós, e que não podem ser reduzidos à relação de semelhança entre o macro e o microcosmo, como foi concebido convencionalmente pela magia, mas se encontram na superfície de nosso cotidiano e podem ser acessados de maneira

\footnotetext{
${ }^{28}$ Cf. FOUCAULT, As palavras e as coisas. Mas não apenas por ele. Agamben afirma que "toda investigação em ciências humanas - e em particular no âmbito histórico - tem necessariamente a ver com as assinaturas" (Signatura rerum, p. 105) como uma espécie de marca própria ao seu tempo que permite ao investigador reconhece-las. Para Deleuze (Foucault, La subjetivación), pensando a partir de Agamben (Signatura rerum), os conceitos implicam assinaturas sem as quais permanecem inertes e improdutivos. W. Benjamin conhece bem a doutrina das semelhanças e a analisa desde a mímica. "A natureza engendra semelhanças: basta pensar na mímica. Mas é o homem que tem a capacidade suprema de produzir semelhanças (...). A criança não brinca apenas de ser comerciante ou professor, mas também moinho de vento e trem" (Magia e técnica, arte e política..., p. 108). Disso decorre, segundo Benjamin, que uma das maiores pobrezas de nossa época reside justamente em contermos experiências muito menores de correspondências mágicas, com a extinção da faculdade mimética, que os homens antigos ou primitivos. Enfocarei melhor a questão das semelhanças com Benjamin ainda nessa tese.

${ }^{29}$ Cf. AGAMBEN, Signatura rerum.

${ }^{30}$ FOUCAULT, Ditos e Escritos II, p. 40.
} 
mais prática do que imaginamos, o que implica nosso gesto de atenção em percebê-los e os senti-los.

Nesses termos, tanto a assinatura como o enunciado funcionam como condição de possibilidade para que a relação consigo ocorra. Não existe semelhança sem assinatura, ou melhor, a natureza não deixa nada sem assinar, em tudo grifa símbolos a serem decifrados. As semelhanças são a um só tempo aquilo que há de mais manifesto e de mais oculto no mundo e as assinaturas são as marcas visíveis das semelhanças invisíveis, os rastros deixados pela natureza que caberiam aos homens decifrar. "A semelhança era a forma invisível daquilo que, no fundo do mundo, tornava as coisas invisíveis; mas para que essa forma, por sua vez, venha até a luz, é necessária uma figura visível que a tire de sua profunda invisibilidade" 31 . Em outras palavras, é como se tudo existente no universo trouxesse hieróglifos singulares que são necessários decifrar. "Não é verdade que todas as ervas, as plantas, as árvores e outros, provenientes das entranhas da terra, são outros tantos livros e sinais mágicos?" 32 .

Nos termos desse círculo mágico regido pelas semelhanças, a assinatura é o que faz falar os movimentos secretos daquilo que existe para fazê-los inteligíveis. Assim como o homem manifesta o seu entendimento pela voz, as ervas mostram o seu potencial terapêutico pelas assinaturas que as demarcam. Não é ao acaso que a noz se assemelha ao cérebro. Eis porque as plantas que são análogas à cabeça, aos olhos, ao coração ou ao fígado terão eficácia curativa sobre o órgão assemelhado. Conhecer, portanto, será decifrar os sinais ocultos que habitam na natureza.

As leis da magia não são senão uma espécie de filosofia experimentada entre os seres e a natureza ${ }^{33}$. Nesses termos, o gesto arqueológico ao se ocupar da magia significa a capacidade de tomar nota das assinaturas celestes grafadas nas imagens disponíveis no mundo. A imagem ganha esse nome porque as forças dos espíritos estão reunidas nela sob a forma de símbolos a serem decifrados, exercício que implica imaginação e transcende ao intelecto e aos juízos determinantes. O mago "é o homem que por dom, experiência ou revelação, conhece a natureza e as naturezas; sua prática é determinada por seus conhecimentos. É aqui que a magia mais se aproxima da ciência" ${ }^{\text {"34. }}$.

O paradigma que rege o jogo das semelhanças acolhe, ao mesmo tempo e no mesmo plano, magia e erudição. A forma de conhecimento entendida dessa maneira não silencia práticas como a astrologia, a fisiognomia e a quiromancia, pois elas ensinam a "decifrar o segredo do 'homem interno' nos signos que os astros imprimiram sobre o rosto e sobre os membros dos homens ou nas linhas de suas mãos" ${ }^{35}$. As práticas mágicas são formas de ler o cosmo que se encontram muito para além dos textos e das teorias. Os saberes divinatórios não concorriam com as formas científicas de conhecimento, mas se incorporavam a eles, pois caberia aos atores da magia - alquimistas, herboristas, bruxas, feiticeiras, etc. - a tarefa de ler aquilo que não fora escrito nos textos e com isso estabelecer um modo de orientação no mundo que pudesse exceder o campo teórico ou intelectual.

\footnotetext{
${ }^{31}$ FOUCAULT, As palavras e as coisas, p. 36.

${ }^{32}$ CROLLIUS apud FOUCAULT, As palavras e as coisas, p. 37.

${ }^{33}$ MAUSS, Sociologia e Antropologia, p. 112.

${ }^{34}$ MAUSS, Sociologia e Antropologia, p. 112.

35 AGAMBEN, Signatura rerum, p. 49.
} 
A assinatura é o lugar onde o gesto de ler e o gesto de escrever invertem a sua relação e entram em uma zona de indecidibilidade. A leitura se faz escritura e a escritura se converte em leitura. A linguagem, como parte das semelhanças e das assinaturas, deve ela própria ser estudada como um elemento inerente à natureza, e não aquilo que confere sentido e significado às coisas. "Seus elementos tem, como os animais, as plantas ou as estrelas, suas leis de afinidade e de conveniência, suas analogias" ${ }^{36}$. Essa compreensão de linguagem se difere substancialmente do conteúdo representativo que ancora a gramática desde os séculos XVII e XVIII ao dotar o homem como ser único da linguagem a interpretar o mundo.

$\mathrm{Na}$ magia, as palavras agrupam sílabas e as sílabas agrupam letras porque existe uma vida própria entre elas. Os magos sabem que existem potências e virtudes escondidas nas palavras por isso não as evocam a esmo. São as virtudes das palavras que aproximam e distanciam aqueles que falam, sendo as palavras os sujeitos cujo objeto é o homem que a pronuncia. Os nomes designam as virtudes ocultadas nas coisas, "como a força está escrita no corpo do leão, a realeza no olhar da águia, como a influência dos planetas está marcada na fronte dos homens: pela forma de similitude" ${ }^{37}$.

Essa disposição epistemológica permite que a linguagem seja um elo de ligação entre o esoterismo e a ciência da natureza. "A linguagem está a meio caminho entre as figuras visíveis da natureza e as conveniências secretas do discurso esotérico (...); é um segredo que traz em si, mas na superfície, as marcas decifráveis daquilo que ele quer dizer" ${ }^{\prime 3}$. Isso acarreta às línguas uma relação com o mundo que não é de significação, mas de analogia, que permite comparar as relações entre os seres e as imagens do mundo habitado.

No Renascimento, a linguagem é ternária, pois há entre o significante e o significado um terceiro elemento, que é justamente a analogia residida pela assinatura (aquilo que une linguagem e seres-natureza-mundo). Tomo como exemplo a presença da doença em determinado ser: a doença é um sujeito que se apossou de um ser-objeto. Entre eles há um terceiro elemento, que seria a correspondência simbólica da assinatura ao convocar uma relação entre doença-sujeito e ser-objeto que tem de ser decifrada para a transformação do ser vivente. Nesses termos, as doenças funcionam como sinais corpóreos para a transformação do espírito.

A leitura arqueológica nos mostra que esse jogo complexo vai desaparecer com o fim do século XVI e o discurso será convertido a uma forma binária, onde a "linguagem não será nada mais que um caso particular da representação (para os clássicos) ou da significação (para nós)"39. Segundo Foucault:

Desaparece então essa camada uniforme onde se entrecruzam indefinidamente o visto e o lido, o visível e o enunciável. As coisas e as palavras vão separar-se. O olho será destinado a ver e somente a ver; o ouvido somente a ouvir. O discurso terá realmente por tarefa dizer o que é, mas não será nada mais do que ele diz. ${ }^{40}$

\footnotetext{
${ }^{36}$ AGAMBEN, Signatura rerum, p. 48.

${ }^{37}$ FOUCAULT, As palavras e as coisas, p. 49.

${ }^{38}$ FOUCAULT, As palavras e as coisas, p. 49.

${ }^{39}$ FOUCAULT, As palavras e as coisas, p. 59.

${ }^{40}$ FOUCAULT, As palavras e as coisas, p. 59.
} 
Só a literatura, para Foucault, permite trazer à lembrança essa maneira de pensar hoje, $\mathrm{Na}$ literatura manifesta-se o reaparecimento do ser vivo da linguagem como contradiscurso, que remonta àquele ser bruto e experiência nua esquecidos desde o século XVI. O romance deriva do mistério e por isso "todo relato - toda literatura - é, nesse sentido, memória da perda do fogo" 41 alquímico.

\section{MANA E A PRIORI HISTÓRICO}

Agamben $^{42}$ é enfático ao afirmar que antes de recorrer à arqueologia filosófica de Kant, como habitualmente se lê, Foucault rouba ${ }^{43}$ a noção de a priori histórico da noção de mana como consta no pensamento de Marcel Mauss em seu Esboço de uma teoria geral da magia (1902-03). Mana $a^{44}$ é a forma preliminar de toda experiência de criação, de forças e condição mesma da experimentação mágica. Conforme sugere Mauss:

Ela escapa a qualquer exame. É dada a priori, previamente a qualquer experiência. Ela não é, propriamente falando, uma representação da magia como o são a simpatia, os demônios, as propriedades mágicas. Ela rege as representações mágicas, é a condição delas, sua forma necessária ${ }^{45}$.

Pensar à maneira da magia exige que desterremos os pressupostos científicos a que fomos formatados na modernidade, uma vez que a magia escapa à lógica da mathesis universalis.

Os termos que implicam a magia são heterogêneos (força, poder, dýnamis, mana, etc.) e se compõem por uma série de ideias instáveis umas nas outras. Dessa maneira, mana rompe com o modelo representacional pelo qual fomos viciados gramaticalmente: “mana não é simplesmente uma força, um ser, é também uma ação, uma qualidade e um estado. Em outros termos, a palavra é ao mesmo tempo um substantivo, um adjetivo e um verbo" ${ }^{46}$.

Ela é sucessivamente e ao mesmo tempo qualidade, substância e atividade e por isso escapa às categorias rígidas de nossa linguagem e de nossa razão. Podemos dizer de um ser, espírito, homem, pedra ou rito que ele tem mana, o mana de fazer isso ou aquilo. Assim, "o mana é a força por excelência (...) é ele que faz que a rede pegue, que a casa seja sólida, que a canoa mantenha-se firme no mar" ${ }^{37}$. Mana é potência e não implica a sua passagem para o

\footnotetext{
41 AGAMBEN, O fogo e o relato, p. 29.

${ }^{42}$ AGAMBEN, Signatura rerum, p. 130.

43 O verbo é usado propositalmente. Embora nunca cite Mauss, Paul Veyne afirma que Foucault lia apaixonadamente esse autor (VEYNE, Foucault: seu pensamento, sua pessoa, p. 46). Além disso, para quem pesquisa Foucault há anos é fácil reconhecer que há não apenas similaridade estilística entre ambos, mas que conceitos empregados por Foucault estabelecem relação íntima ao pensamento de Mauss.

${ }^{44} \mathrm{O}$ mana não é universal, mas se trata de uma ressonância comum a certo número de sociedades. Independente da nomenclatura, Mauss identifica que uma noção comum encontra-se como base para a execução dos ritos mágicos.

45 MAUSS, Sociologia e antropologia, p. 152.

${ }^{46}$ MAUSS, Sociologia e antropologia, p. 142.

${ }^{47}$ MAUSS, Sociologia e antropologia, p. 145.
} 
ato. Dessa maneira, não se pode querer examinar o mana com o olhar crítico ocidental habitual.

Mana é uma espécie de categoria inconsciente do intelecto e funciona como um meio que torna possível os atos de pensamento e criação, transcendendo ao próprio humano. Mana sugere que os modelos epistemológicos escapam às leis objetivas da dedução e da indução, que há neles uma forma de imaginação ativa nem sempre explicável e por isso incapaz de obedecer à lógica da homogeneidade nem da consciência. De modo diferente a isso, parece existir uma forma de constelação histórica formada por potências secretas e forças misteriosas no pensamento individual e coletivo que possibilitam ao espírito comunicar-se com uma espécie de "quarta dimensão" do espaço quando se relaciona com outras subjetividades e afetos e por isso transcende a mera realidade acessada pelos nossos cinco sentidos ao contactarmos os objetos.

Mauss aponta que, na Grécia, berço de nossa tradição filosófica ocidental, pode-se encontrar o mana sob a forma de phýsis (natureza) e dýnamis (potência), noções advindas do universo mágico, embora na atualidade toda a sua dimensão mística fosse esvaziada de modo a subsistir essa noção subsiste apenas enquanto ossatura científica:

Ali a encontramos sob o aspecto da phýsis, na qual se detém, em última análise, os alquimistas, e também da dýnamis, instância última da astrologia, da física e da magia. A dýnamis é a ação da phýsis, e esta é o ato da dýnamis. E pode-se definir a phýsis como uma espécie de alma material, não individual, transmissível, uma espécie de inteligência inconsciente das coisas. Em suma, ela é também muito próxima do mana ${ }^{48}$.

Mana é pensar desde a potência não apenas dos seres, mas também das coisas. Mana seria essa potência secreta que nos é dada anterior à experiência e evoca um poder mágico a todos os seres, para além dos humanos. Como tal, ela pouco pode ser pensada desde os saberes racionais, letrados e eruditos.

Há uma espécie de inteligência inconsciente, ontologia mágica que habita o som que as coisas e os seres emitem, os encantamentos e as evocações, as possessões, os sonhos, os ciclos astrológicos etc. Haveria, portanto, uma dimensão esotérica que pertence à certa zona desconhecida e misteriosa que nos habita. A arqueologia do saber ganharia assim uma dimensão ontológica própria, que aposta na ideia de que o aparecimento de determinada relação com o conhecimento num determinado período e cultura não obedece ao acaso. Em cada época existiria certo código de saber sistematizado entre as franjas mágicas da história onde novidades emergem.

É por isso que Foucault lança a argumentação de que existiria um inconsciente positivo do saber, uma espécie de a priori histórico que escapa à forma científica dos saberes especializados e a consciência do pesquisador à medida que se desloca da maneira racional e objetiva de pensar: os ilustrados não se deram conta de onde estavam os limites que os permitiam ver e dizer e nós mesmos pouco podemos predizer qual novidade emergirá no umbral de nosso presente. Esse a priori não obedece a qualquer destinação da história, como

${ }^{48}$ MAUSS, Sociologia e antropologia, p. 151. 
se tudo já fosse previamente escrito, mas sim aos campos de forças e potências que ditam condições de possibilidades para os saberes, as práticas e todo um campo científico.

A grande novidade em termos de análise fica por conta de que esse todo esse movimento obedece a um tipo de coerência e compreensão que cruzam sincronia e diacronia aos acontecimentos ${ }^{49}$. Dois ou mais enunciados se dispersam simultaneamente estando relacionados entre si por formas acausais. A sincronia não é nem cronológica, onde um evento se assume em sequência do outro, nem casual, onde eles se ligariam de modo fortuito. Não obstante, haveria entre eles uma forma diacronia sucessiva no correr do tempo que encadeia os acontecimentos como se encadeiam as frequências na música experimental da vida: ainda que não sejam harmônicas como em uma orquestra, os campos de forças regem um tipo de vibrações próprias que enlaçam as semelhanças e as diferenças entre os seres. Haveria nesse a priori histórico uma espécie de força paradigmática que concentra as condições de possibilidades para os campos epistemológicos regentes em cada época e espaço. Uma assinatura.

Não se pode restringir o pensamento mágico ao modelo humanista, que liga a vida permanentemente aos julgamentos de valores baseados "em certas concepções do homem que são tomadas emprestadas da religião, das ciências e da política" 50 porque ele permite questionar as fronteiras entre natureza e cultura e também nos alerta de que não seríamos tão conscientes e senhores da nossa própria vida, como o discurso do esclarecimento nos fez acreditar. Vale lembrar que a magia se estabelece entre o umbral da consciência e da inconsciência, na superfície daquilo que cruza o visível e o invisível, destino e acaso.

\section{IMPLICAÇÕES ÉTICO-ESPIRITUALISTAS}

A título de considerações finais, a leitura diagonal e filosófica que teço convoca pensarmos a arqueologia como uma espécie de anticiência de assinaturas, mais próximo do que Foucault denomina por enunciado, o qual opera a função de existência que cruzaria as palavras e as coisas e parece orientar a psique através de sinais que lhe são enviados pelo cosmo. Tal cruzamento possibilita resgatar linhas de fuga epistemológicas silenciadas pela ascensão do pensamento ilustrado e pelo modelo científico e humano que vigora na atualidade. Nesses termos, do mesmo modo com que a arqueologia engloba uma zona fronteiriça de disciplinas - como a hermenêutica, o estruturalismo, a semiologia ou a psicanálise - e delas se difere, procurei mostrar que o exercício arqueológico foucaultiano também ancora as suas noções essenciais na magia, práticas de transformação de si condenadas ao silenciamento pela maneira disciplinar, científica e humanista de pensar.

Por exemplo, tanto os enunciados são as assinaturas que conjuntos de signos (pode ser uma frase, uma proposição, um símbolo, etc.) recebem pelo direito de existirem, como a prática discursiva é extraída da noção de sina ${ }^{\not 1}$. Ademais, procurei mostrar como o pensamento arqueológico funciona tomando uma relação estreita entre o a priori histórico e

\footnotetext{
${ }^{49}$ FOUCAULT, $A$ arqueologia do saber, p. 151.

${ }^{50}$ FOUCAULT, Ditos e Escritos II, p. 342.

${ }^{51}$ Cf. DOSSE, Renascimento do acontecimento, p. 161.
} 
o mana, condição mesma da experimentação da magia e da criação em geral. Essa relação permite causar uma inteira problematização da maneira intelectual com que o humano restringiu a sua forma de pensar ${ }^{52}$.

O que a arqueologia foucaultiana parece produzir em termos de novidade histórica é pensar o paradigma das semelhanças, à luz da própria filosofia da diferença, excedendo a magia para além dos postulados entre analogia e simpatia, ancorando-os nos termos de uma ontologia do presente que pudesse friccionar os saberes humanistas pelos quais o sono antropológico confinou um tipo de filosofia crítica. Quando magia e filosofia se encontram, podem ser ensaiadas - em termos de cuidado e espiritualidade - outras regras do jogo, que excederiam técnicas de si em geral reduzidas ao campo artístico. Movimento presente nos últimos cursos de Foucault.

É filosofia o deslocamento e a transformação dos parâmetros de pensamento, a modificação dos valores recebidos e todo o trabalho que se faz para pensar de outra maneira, para fazer outra coisa, para tornar-se diferente do que se é. ${ }^{53}$

Tornar-se diferente do que se é, eis o mote da ética pensada por Michel Foucault. A ética é uma atividade intimamente relacionada à experimentação da liberdade como possibilidade de buscar por outras maneiras de viver, as quais não implicam na renúncia de si, mas convoca outro tipo de espiritualidade enquanto força criadora do ser.

No horizonte de seu projeto filosófico, o não condicionamento do saber e do discurso à ciência e à disciplina já percebido em seu período arqueológico abre também outras possibilidades de nos relacionarmos eticamente. Ética aqui deve ser entendida pela maneira como cada um se relaciona consigo mesmo, o modo como nos autorizamos ou não a praticar certa coisa, a fazer isto e não aquilo ${ }^{54}$. Esta relação reverbera no conjunto de afetividades vividas com o outro - tanto o outro de nós mesmos como os outros em geral e também para com o mundo habitado. Dessa maneira, o sujeito se constitui e se transforma em indissociável relação imanente à própria vida - como ator e objeto - daquilo que cria em sua existência.

Nessa senda, um caminho para pensarmos a ética aliada à espiritualidade enquanto o trabalho estabelecido como diferenciação sobre aquilo que somos parece menos complexo do que imaginamos: não reside em Deus, como lido pela tradição dualista e transcendente, tampouco numa vida exterior que não seja essa, mas estaria cravada nas insígnias de nós mesmos, assinaturas pensadas enquanto enunciados existentes no próprio corpo em que habitamos aqui e agora. É por isso que a arqueologia encontra na magia uma atitude-limite em forma de crítica situada nas fronteiras entre a semelhança e a diferença, "como pesquisa histórica através dos acontecimentos que nos levaram a nos constituir e a nos reconhecer como sujeitos do que fazemos, pensamos, dizemos" ${ }^{~} 55$, o que poderia nos mostrar um tipo

\footnotetext{
${ }^{52}$ Cf. MAUSS, Sociologia e antropologia, p. 142.

${ }^{53}$ FOUCAULT, Ditos e Escritos II, p. 305.

${ }^{54}$ Cf. GROS, Desobedecer, p. 21.

${ }^{55}$ FOUCAULT, Ditos e Escritos II, p. 348.
} 
de ethos que não silenciasse os saberes ligados a loucura como o extraordinário da vida no tempo presente.

\section{ARCHEOLOGY AND MAGIC}

Abstract: Nature leaves nothing without signing. Such gesture of emitting signals sounds like an ethical purpose that cannot be understood in the light of the human sciences. From a different perspective of the contemporary scientific discourse, the general purpose of this paper will be to describe the game of shadows by which Michel Foucault's archeology approaches the paradigm of magic. Magic is a spiritual practice with oneself, with one another, and with the world, which cannot be reduced to the representation and the meaning. My hypothesis tries to investigate to what extent the paradigm of magic is present in the archaeological writings, even though Michel Foucault scarcely refers directly to it, a task that implies an excavation of the tracks left between the lines of his thought, as did his contemporary Giorgio Agamben. To this end, I will focus on the resonance between the concepts of (a) statement and signature and (b) historical a priori and mana. We acknowledge that statement and historical a priori are two central operators to the archaeological thought. My task will be to show that they are intimate with signature and mana, both notions from the field of magic. It will not be difficult to realize that archeology drinks like a fish the paradigm of magic. Such interpretation allows us to think how knowledge and practices have been eclipsed since secularized thinking and Enlightenment. Thus, archeology is signalized as a kind of anti-science of signatures, a kind of an ethos which is unveiled so far.

Keywords: archeology - magic - statement - signature - Michel Foucault.

\section{REFERÊNCIAS BIBLIOGRÁFICAS}

AGAMBEN, G. Signatura rerum - sobre el método. Córdoba: Adriana Hidalgo Editora, 2009.

O fogo e o relato: ensaios sobre criação, escrita, arte e livros, trad. Andrea Santurbano, Patricia Peterle, $1^{a}$ ed. São Paulo: Boitempo, 2018.

BENJAMIN, W. Destino e caráter. In: Iluminationem. Frankfurt: Fischer Verlag, 1981.

Magia e técnica, arte e política: Ensaios sobre literatura e história da cultura, obras escolhidas vol. 1, Trad. Sergio Paulo Rouanet, $3^{\text {a }}$ ed. São Paulo: Editora Brasiliense, 1987.

CARVALHO, A. F. "Foucault e a espiritualidade como o real da filosofia: do ultrapassamento de si ao ultrapassamento do mundo". Fermentario, no 8, Vol. 2, p. 1 - 16, 2014.

Anarqueologia e aleturgia em Foucault: $\chi^{\mathrm{e}}$ se as verdades fossem outras para a educação? In: CORTÉS, O. P.; VACA, M. T. S.; BERNAL, O. O. E; (org). Pensar de otro modo. Herramientas filosóficas para investigar en educación. Tunja, Editorial UPTC: 2017.

DELEUZE, G. Foucault. Trad. Claudia Sant'Anna Martins; revisão Renato Janine Ribeiro. São Paulo: Brasiliense, 2013. 
La subjetivación: curso sobre Foucault III, $1^{\mathrm{a}}$ ed., Ciudad Autónoma de Buenos Aires: Cactus, 2015.

DÍAZ, E. A filosofia de Michel Foucault. Trad. Cesar Candiotto, $1^{\text {a }}$ ed. São Paulo: Editora Unesp, 2012.

DREYFUS, H. RABINOW, P. Michel Foucault: Uma Trajetória Filosófica (para além do estruturalismo e da hermenêutica). Trad. Vera Porto Carrero. Rio de Janeiro: Forense Universitária, 1995.

DOSSE, F. Renascimento do acontecimento: um desafio para o historiador: entre Esfinge e Fênix. Trad. Constancia Morel, São Paulo: Editora Unesp, 2013.

FEDERICI, S. Calibã e a bruxa: mulheres, corpo e acumulação primitiva. Trad. Coletivo Sycorax, São Paulo, Elefante, 2017.

FOUCAULT, M. As palavras e as coisas. Uma arqueologia das ciências humanas. Trad. Salma Tannus Muchail, $8^{a}$ ed., Martins Fontes: São Paulo, 2002.

A arqueologia do saber. Trad. Luiz Felipe Baeta Neves, $7^{\mathrm{a}}$ ed. Rio de Janeiro: Forense Universitária, 2008a.

Ditos e Escritos II. Arqueologia das ciências e história dos sistemas de pensamento.

Org. e Sel. De Textos Manoel Barros da Motta. Trad. Elisa Monteiro, $2^{\mathrm{a}}$ ed., Rio de Janeiro: Forense Universitária, 2008b.

FREITAS, A. S. de. "O cuidado de si e os perigos de uma ontologia ainda sem cabimento: o legado ético-espiritual de Foucault”. Pro-posições. v. 25, nº 2 (74), p. 121-138, maio-ago, Campinas-SP, 2014.

GERNET, L. Antropología de la Grecia Antigua. Madrid: Taurus, 1984.

GROS, F. Desobedecer. Trad. Célia Euvaldo, São Paulo: Ubu Editora, 2018.

LECOURT, D. A Arqueologia e o Saber. In: O Homem e o Discurso: A arqueologia de Michel Foucault. $2^{a}$ ed. Rio de Janeiro: Tempo Brasileiro, 1996.

MACHADO, R. A arqueologia do saber e a constituição das ciências bumanas. Ano V, n ${ }^{\circ}$. São Paulo: Revista Discurso (USP), 1974.

Foucault, a ciência e o saber. $4^{\mathrm{a}}$ ed. Rio de Janeiro: Zahar, 2009.

MAUSS, Marcel. Sociologia e antropologia. São Paulo: Cosac \& Naify, 2003.

PERENCINI, T. B. "O enunciado no pensamento arqueológico de Michel Foucault". Kinesis, v.VII, nº 15, p. 135-150, Marília-SP, 2015.

- Uma arqueologia do ensino de filosofia no Brasil: Formação discursiva na produção acadêmica de 1930 a 1968. São Paulo: Cultura Acadêmica, 2017. 
. "Tarot como prática possível ao processo de individuação". Revista Jung Marília, Vol. 1, n. 1, p. 10-34, Marília-SP, 2018.

STENGERS, I. No tempo das catástrofes - resistir à barbárie que se aproxima, Trad. Eloisa Araújo Ribeiro, São Paulo: Cosac Naify, 2015.

"Reativar o animismo". Cadernos de Leitura, n 62, Belo Horizonte: Edições Chão da Feira, 2017.

VEYNE, P. Foucault: seu pensamento, sua pessoa. Trad. Marcelo Jacques de Morais, Rio de Janeiro: Civilização Brasileira, 2011. 